\title{
Hassas Nokta Konumlama Yönteminin Kabuk Deformasyonu Belirleme Çalışmalarında Kullanılabilirliğinin Araşstırılması
}

\author{
Investigating the Potential of Precise Point Positioning in Crustal Deformation Studies
}

\author{
Sefa YALVAÇ* \\ Gümüşhane Üniversitesi, Mühendislik ve Doğa Bilimleri Fakültesi, Harita Mühendisliği Bölümü, 29100, Gümüşhane
}

\begin{abstract}
• Geliş tarihi / Received: 09.04.2019 • Düzeltilerek geliş tarihi / Received in revised form: $27.05 .2020 \quad$ • Kabul tarihi / Accepted: 01.06 .2020
\end{abstract}
\begin{abstract}
$\ddot{\mathbf{O z}}$
$\mathrm{Bu}$ çalışmada, HNK (Hassas Nokta Konumlama) yönteminin kabuk deformasyonu belirleme çalışmalarında kullanılabilirliği, rölatif GNSS (Global Navigation Satellite System) analizleri eşliğinde araştırılmıştır. Bu amaçla, Kuzey Anadolu Fay (KAF) hattının kuzeyinde yer alan GIRS, SINP ve ZONG istasyonları ile söz konusu fay hattının güney kesiminde konumlanan RHIY, ANKR ve BILE TUSAGA-Aktif (Türkiye Ulusal Sabit GNSS Ağ1-Aktif) istasyonlarının 2011-2018 (8 yıl) yılları arasındaki periyodik verileri elde edilerek analiz edilmiştir. Analizler, HNK yöntemi için CSRS PPP (Canadian Spatial Reference System Precise Point Positioning) çevrimiçi servisiyle, rölatif yöntem için ise GAMIT/GLOBK V10.7 akademik GNSS analiz yazılımı yardımıyla gerçekleştirilmiştir. Koordinat değerleri Kalman filtreleme tekniği yardımıyla analiz edilerek, her istasyona ait hız değerleri Avrasya plakasında konumlanan ORID IGS (International GNSS Service) istasyonu sabit olarak Kuzey, Doğu ve Yukarı bileşenler için ayrı ayrı kestirilmiştir. Her iki yöntemden elde edilen hız kestirim değerleri arasındaki farklardan hesaplanan üç boyutlu konum hatası değerlerinin $0.1 \mathrm{~mm}$ ile $2.4 \mathrm{~mm}$ seviyeleri arasında olduğu ve HNK yönteminin bilimsel kabuk deformasyonu belirleme çalışmalarında kullanılabileceği sonucuna varılmıştır.
\end{abstract}

Anahtar kelimeler: GNSS, HNK, Kabuk Deformasyonu, Mutlak Konumlama, Rölatif Konumlama

\begin{abstract}
In this study, the potential of PPP (Precision Point Positioning) method in crustal deformation studies was investigated with the help of relative GNSS (Global Navigation Satellite System) analyses. For this purpose, data of six GNSS stations, three (GIRS, SINP and ZONG) of which are located to the north of the North Anatolian Fault (NAF) zone and the other three (RHIY, ANKR and BILE) are located to the south of the NAF zone, were obtained and analyzed between the years of 2011-2018 (8 years long). The analyzes were carried out by means of the CSRS online service for the PPP method and the GAMIT / GLOBK V10.7 academic GNSS analysis software for the relative positioning technique. The obtained coordinates are analyzed with the help of Kalman filter to estimate the velocities of each station for the North, East and Up components as fixed on the ORID IGS (International GNSS Service) station which located on the Eurasian plate. It was found that the $3 D$ positioning error calculated from the velocity differences between the both methods ranged from $0.1 \mathrm{~mm}$ to $2.4 \mathrm{~mm}$ levels. Thus, it is concluded that PPP method can be used successfully in crustal deformation studies.
\end{abstract}

Keywords: GNSS, PPP, Crustal Deformation, Absolute Positioning, Relative Positioning

*Sefa YALVAÇ; sefayalvac@gmail.com; Tel: (0456) 2331000 (1762); https://orcid.org/0000-0002-8989-6231 


\section{Giriş}

GNSS (Global Navigation Satellite System) tekniği, sivil kullanıma sunulmasından bu yana özellikle jeodezi alanına büyük kolaylıklar sunmuş ve beraberinde getirdiği birçok avantaj ile klasik yersel ölçme tekniklerinin yerini hızla almıştır. Her zaman ve her yerde, her türlü hava koşulunda, global bir koordinat sisteminde, yüksek hassasiyette 3B konum üretebilen GNSS tekniği, bu özellikleri sebebiyle kabuk deformasyonu belirleme çalışmalarında da sıklıkla tercih edilmektedir (Ustun vd., 2010; Yalvaç, 2020b).

Çoğu jeodezik çalışmada olduğu gibi kabuk deformasyonu belirleme çalışmaları da yüksek hassasiyet gerektiren çalışmalar arasındadır. Söz konusu çalışmalarda yatayda birkaç milimetre düşeyde ise santimetre altı hassasiyet beklenir. Böylesi bir hassasiyeti elde edebilmek için GNSS ağ1 homojen bir yapıda tasarlanır ve GNSS gözlemleri, statik GNSS oturumları eşliğinde ardışık günlerde tekrarlı olarak gerçekleştirilir. Ölçüler yapılırken ağ geometrisinin ve ölçü planının değişmemesine özen gösterilir (Baarda, 1968). Elde edilen gözlemler birçok hata kaynağının faz farkları yardımıyla elemine edilebildiği rölatif konumlama yöntemine göre yap1lır (Herring vd., 2010; Aydin vd., 2019). Bu durum göz önünde bulundurularak noktalar arasındaki baz uzunluklarının belirli sınırlar içerisinde kalması sağlanır (Amiri-Simkooei vd., 2017). Ayrıca, rölatif GNSS tekniğiyle ile konum belirlemede yukarıda bahsedilen hassasiyet değerlerinin elde edilebilmesi için GAMIT/GLOBK, BERNESE ve GIPSY OASIS gibi GNSS konusunda deneyim sahibi kişilerin kullanabileceği bilimsel analiz yazılımlarının da yer almas1 neredeyse zorunludur (Aydin vd., 2019). Tüm bu parametreler rölatif konumlama yöntemi ile yapılan deformasyon izleme çalışmalarında kısıtlayıcı birer parametre olarak karşımıza çıkmaktadır.

Öte yandan, 1990 y1lı sonlarında NASA JPL (Jet Propulsion Laboratory) tarafindan, herhangi bir sabit noktaya ihtiyaç duymayan, tek bir GNSS alıcısı ile $\mathrm{cm}$-dm seviyelerinde doğruluk elde edilmesine imkan tanıyan bir nokta konumlama yöntemi geliştirildi ve Precise Point Positioning (Türkçe: Hassas Nokta Konumlama) olarak isimlendirildi (Nistor ve Buda, 2015).

Hassas Nokta Konumlama (HNK) yöntemi ile nokta konumunun elde edilmesinde doğrudan uydu-alıcı anteni arasındaki uzunluk esas alınır.
$\mathrm{Bu}$ nedenle, rölatif nokta konumlama yöntemini kısıtlayan ağ geometrisinin ve ölçü planının sabit kalması, GNSS istasyonları arası baz uzunluklarının belirli bir sınır içerisinde tutulması ve jeodezik ağın bir referans sistemine taşınması için bölgesel istasyonlara ihtiyaç duyulması gibi kısitlamalar bu yöntem ile konum belirlemede giderilmiştir (Zhou vd., 2018). Ancak, mutlak konumlamayı esas alan HNK yönteminde, faz farkları oluşturulamadığından, alıcı saati hatası elemine edilemez ve başlangıç tamsayı belirsizliği çözümü için de belirli bir yakınsama süresine ihtiyaç duyulur (Yalvaç, 2019). Analiz için gerekli olan alıcı saati hataları kestirilmek ve yörünge parametreleri de GNSS ürünlerinden temin edilmek suretiyle elde edilir. Ancak yöntemin geliştirildiği dönemlerde, oldukça kısıtlı merkez tarafindan gerçekleştirilen GNSS ürünleri ve bu ürünlerin doğruluklarının günümüze göre nispeten düşük olması HNK yönteminin o dönemlerde, özellikle jeodezide yüksek hassasiyet beklenilen çalışmalarda kullanımını kısıtlamıştır.

Son 10 yıllık süreçte, GNSS uydularının sayısının artmas1, modernizasyonu ve IGS (International GNSS Service) başta olmak üzere, Jet Propulsion Laboratory (JPL), Center for Orbit Determination in Europe (CODE), GFZ (German Research Center for Geoscience), Wuhan üniversitesi gibi hassas saat ve yörünge parametrelerini üreten ajansların artmasıyla birlikte hem gözlenebilir uydu sayısı hem de GNSS ürünlerinin doğruluğu artmıştır (Yiğit vd., 2016a). Bu durum, hem HNK yönteminden elde edilen doğruluğun artması hem de yakınsama süresinin kısalması ile sonuçlanmış ve yöntemin doğruluğu rölatif nokta konumlama hassasiyeti seviyelerine oldukça yaklaşmıştır (Yiğit vd., 2016a; Bahadur ve Nohutçu, 2018). Ek olarak, son zamanlarda HNK yöntemi ile analiz yapılabilmesine imkan tanıyan, oldukça basit arayüze sahip, birçok çevrimiçi servis ve ücretsiz yazılım literatüre girmiştir (Tétreault vd., 2015; Zhou vd., 2018). Operasyonel kolaylık, düşük maliyet, sabit istasyon zorunluluğunun ortadan kalkması, analizlerin hızlı ve çevrimiçi gerçekleştirilebilmesi gibi nedenler, HNK yönteminin son yıllarda yaygın olarak kullanılmasına neden olmuştur. Böylece jeodezide yüksek hassasiyet gerektiren deformasyon belirleme çalışmalarında, rölatif konum belirleme yerine kullanılabilirliği de bir araştırma sorusu olarak akla gelmektedir.

Literatür incelendiğinde, HNK yönteminin deformasyon belirleme çalışmalarında kullanılabilirliğinin yatay bileşende ( 2 boyutlu) incelendiği (Yiğit vd., 2016b; Aydin vd., 2019), 
sadece zemin çökmeleri çalışmalarında yükseklik bileşenin (tek boyutun) değerlendirildiği (Yalvac, 2020a), farklı atmosferik koşullar altında HNK yönteminden elde edilen yükseklik bilgisinin araştıııldığı (Rajner ve Liwosz, 2011) ve multiGNSS çözümleriyle HNK yönteminden elde edilen zaman serilerinin karşılaştırıldığ 1 çalışmalar olduğu görülmektedir (Yiğit vd., 2016a). Ancak, son yillarda GPS ve GLONASS sistemlerinin modernizasyonu ve GNSS ürünlerinin kalitesindeki yüksek ivmeli artış göz önünde bulundurulduğunda, üç boyutlu ağlarda HNK yönteminin kabuk deformasyonu belirleme çalışmalarındaki performansının ortaya konulması hala araştırılmaya muhtaç bir konu olarak görülmektedir.

$\mathrm{Bu}$ çalışmada, HNK yönteminin kabuk deformasyonu belirleme çalışmalarında kullanılabilirliği araştırılmıştır. $\mathrm{Bu}$ amaçla, üç tanesi Kuzey Anadolu Fay (KAF) hattı kuzeyine ve diğer üç tanesi de KAF hattı güneyinde konumlanan, 5 tanesi TUSAGA-Aktif (Türkiye Ulusal Sabit GNSS A $\breve{g} 1-$ Aktif) ve bir tanesi de IGS ağına ait toplam 6 istasyonun, 2011-2018 y1llarını kapsayan periyodik verileri elde edilerek HNK ve rölatif GNSS analizleriyle ayrı ayrı değerlendirilmiştir. Elde edilen günlük çözümlerden, Avrasya plakasında bulunan ORID IGS istasyonu sabit hiz değerleri Kalman filtreleme yöntemiyle kestirilmiştir. Her iki yöntemden elde edilen sonuçlar arasındaki farkl11ıklar değerlendirilerek, yeni bir analiz tekniği olan HNK yönteminin kabuk deformasyonu belirleme çalışmalarındaki kullanılabilirliği sayısal olarak ortaya konulmuştur.

\section{Yöntem}

\subsection{GNSS Ăğııın Oluşturulması}

GNSS ağının olușturulması amaciyla TUSAGAAktif ve IGS (International GNSS Serice) ağına ait, KAF hattı kuzeyinde yer alan GIRS, SINP, ZONG ve Güney kesiminde konumlanan RHIY, ANKR ve BILE istasyonları analiz için seçilmiştir (Şekil 1). Bu istasyonların seçiminde, Kuzey Anadolu Fayını (KAF) çevrelemesi, fay hattının her iki yakasında homojen dağılmış olması, sinyal yansımasi hatasindan etkilenmemesi gibi parametreler göz önünde bulundurulmuştur. Söz konusu istasyonların 2011-2018 (8 yıl) yılları aralığındaki 30 sn. kayıt aralıklı gözlem verileri her yıl için 4 periyot (Şubat, Mayıs, Temmuz ve Aralık ayları) ve her periyotta ardışık üç gün için TUSAGA-Aktif sunucularından elde edilerek analiz edilmiştir. Analizlere ait detaylar alt başlıklarda sunulmaktadır.

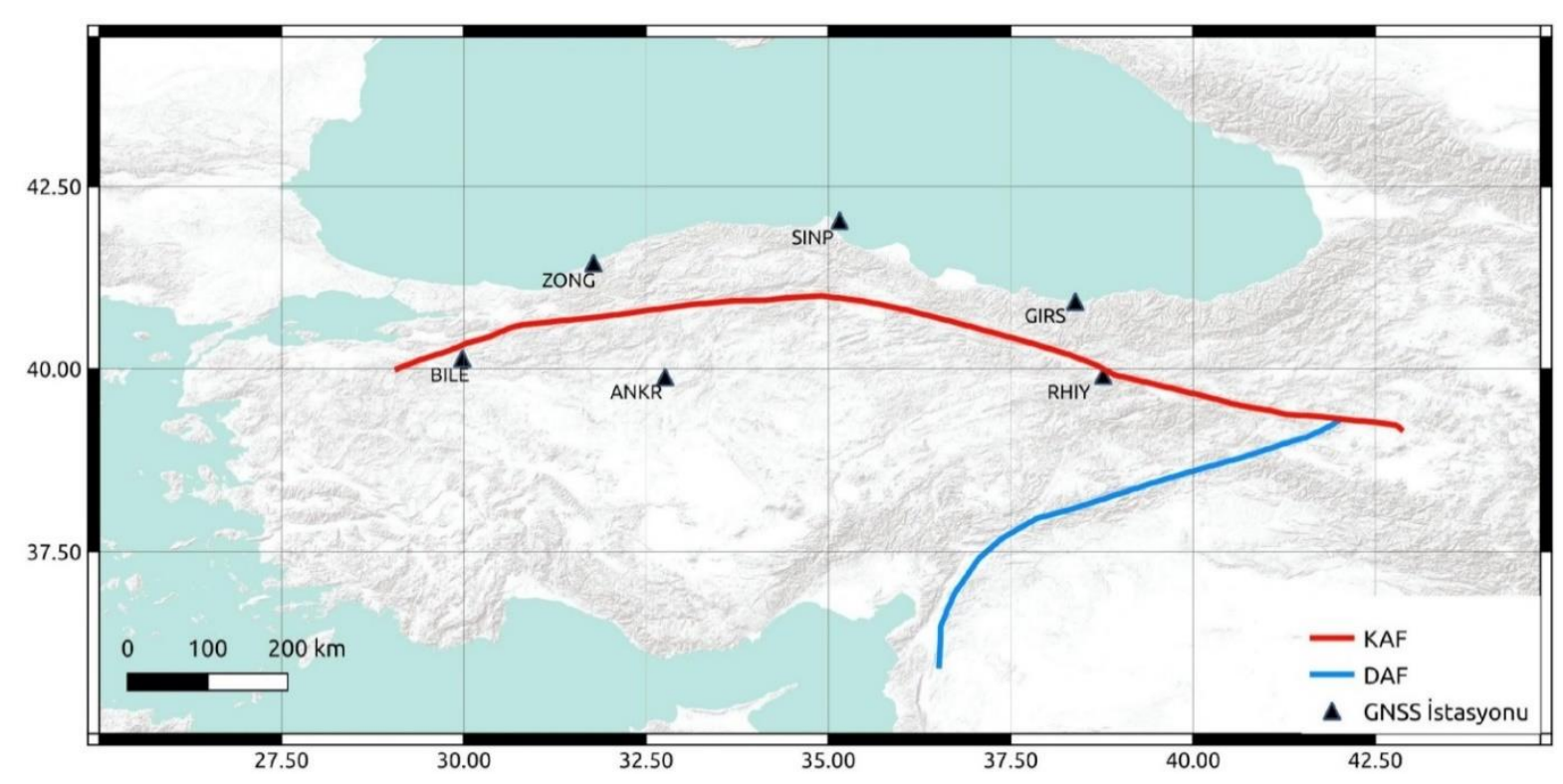

Şekil 1. Analizlerde kullanılan GNSS istasyonları ve fay hatları (DAF: Doğu Anadolu Fayı, KAF: Kuzey Anadolu Fay1)

\subsection{GNSS Analizlerinin Gerçekleştirilmesi}

GNSS analizleri rölatif ve mutlak yöntemlerle ayrı ayrı gerçekleştirilmiştir. Rölatif yöntemle yapılan GNSS analizlerinde GAMIT/GLOBK V10.7 yazılımı kullanılmıştır. Söz konusu yazılım ile yapılan analizler temel olarak 3 aşamadan oluşmaktadır. Bunlardan ilki GAMIT modülü ile günlük çözümlerin oluşturulmasıdır. GAMIT modülü ile çözümler, her istasyonda eş zamanlı 
kaydedilen faz gözlemlerinden (L1 ve L2) oluşturulan iyonosferden bağımsız kombinasyonlar (LC) ile k1smi iz-minimum esasında (ANKR sabit) ve en küçük kareler prensibine göre gerçekleştirilmiştir. Günlük çözümler için hassas yörünge ve saat parametreleri IGS'den elde edilmiş, ağ zorlaması yatayda ve düşeyde $5 \mathrm{~cm}$ seviyeyle yapılmıştır. İkinci aşamada, günlük bazda elde edilen çözümler ITRF (International Terrestrial Reference Frame) sistemine dönüştürülmesi gerçekleştirilmiştir. $\mathrm{Bu}$ amaçla, yazılıma ait GLORG modülü kullanılarak, koordinatları ve hızları ITRF sisteminde tanımlı, Türkiye ve yakın çevresinde konumlanan (yaklaşı $1000 \mathrm{~km}$ ) 10 IGS istasyonu vasıtasıyla, günlük çözümler birkaç mm'lik dönüşüm hataları eşliğinde Helmert transformasyonu ile ITRF08 sistemine taşınmıştır. $\mathrm{Bu}$ sayede aynı referans sisteminde tanımlanan günlük çözümlere ait zaman serileri de oluşturulmuştur. Son aşama, deformasyonların kestirildiği GLOBK aşamasıdır. Bu aşamada, GAMIT yardımıyla günlük çözümler sonucu kestirilen koordinat ve varyans-kovaryans matrisleri GLOBK modülü ile değerlendirilmiştir. GLOBK modülü Kalman filtreleme görevini yerine getirerek analiz süresince meydana gelen deformasyonları kestiren bir araçtır (Herring vd., 2010).

Mutlak yöntemle yapılan analizler HNK yöntemi ile gerçekleştirilmiştir. HNK yöntemine göre yapılan analizler, çevrimiçi analiz servislerinden olan ve bugüne kadar birçok akademik çalışma için tercih edilen, CSRS PPP (Canadian Spatial
Reference System Precise Point Positioning) kullanılarak yapılmıştır. Analizler statik modda, hassas yörünge parametreleri (IGS) eşliğinde ve GPS, GLONASS verileri kullanılarak $7.5^{\circ}$ uydu yükseklik açısı altında gerçekleştirilmiştir. ITRF08 sisteminde elde edilen koordinatlar varyans-kovaryans matrisleri ve genişletilmiş analiz raporlarıyla birlikte, kısa bir süre sonra belirtilen e-posta adresine ulaşmıştır.

\section{Bulgular}

$\mathrm{Bu}$ bölümde, Şekil 1'deki GNSS ağında 20112018 yılları arasinda yapilan analizlerden elde edilen hiz kestirim değerleri rölatif ve HNK yöntemleri için ayrı ayrı sunulacak ve sayısal değerler karşılaştırılacaktır.

Rölatif yöntemden elde edilen günlük çözümler, GLOBK modülü ile birleştirilerek, KAF hattının Kuzey ve Güney bölümlerinde kalan istasyonların hız değerleri Avrasya plakası üzerinde konumlanan ORID istasyonu sabit olarak elde edilmiştir. Elde edilen değerler sayısal olarak Tablo 1'de, hız değerleri hata elipsleri ile birlikte Şekil 2'de gösterilmektedir.

HNK yöntemiyle elde edilen günlük çözümler, varyans-kovaryans matrisleri de göz önünde bulundurularak Kalman filtreleme tekniği ile birleştirilerek hız değerleri yine ORID istasyonu sabit kestirilmiştir. Elde edilen değerler Tablo 2'de sunulmuştur.

Tablo 1. Rölatif GNSS analiz ile elde edilen ORID sabit nokta hızları (mm/yıl) ve standart sapmaları

\begin{tabular}{cccc}
\hline İstasyon & Kuzey $\pm \boldsymbol{\sigma}(\mathbf{m m})$ & Doğu $\pm \boldsymbol{\sigma}(\mathbf{m m})$ & Yukarı $\pm \boldsymbol{\sigma}(\mathbf{m m})$ \\
\hline RHIY & $6.29 \pm 0.12$ & $-11.32 \pm 0.21$ & $-1.09 \pm 2.54$ \\
GIRS & $2.55 \pm 0.13$ & $1.01 \pm 0.27$ & $-1.95 \pm 2.42$ \\
SINP & $1.96 \pm 0.11$ & $0.77 \pm 0.12$ & $-2.36 \pm 1.77$ \\
ANKR & $-0.94 \pm 0.24$ & $-21.35 \pm 0.17$ & $-3.17 \pm 2.24$ \\
ZONG & $1.85 \pm 0.21$ & $0.70 \pm 0.13$ & $-4.69 \pm 2.33$ \\
BILE & $-2.35 \pm 0.35$ & $-21.45 \pm 0.15$ & $-0.72 \pm 3.34$ \\
\hline
\end{tabular}




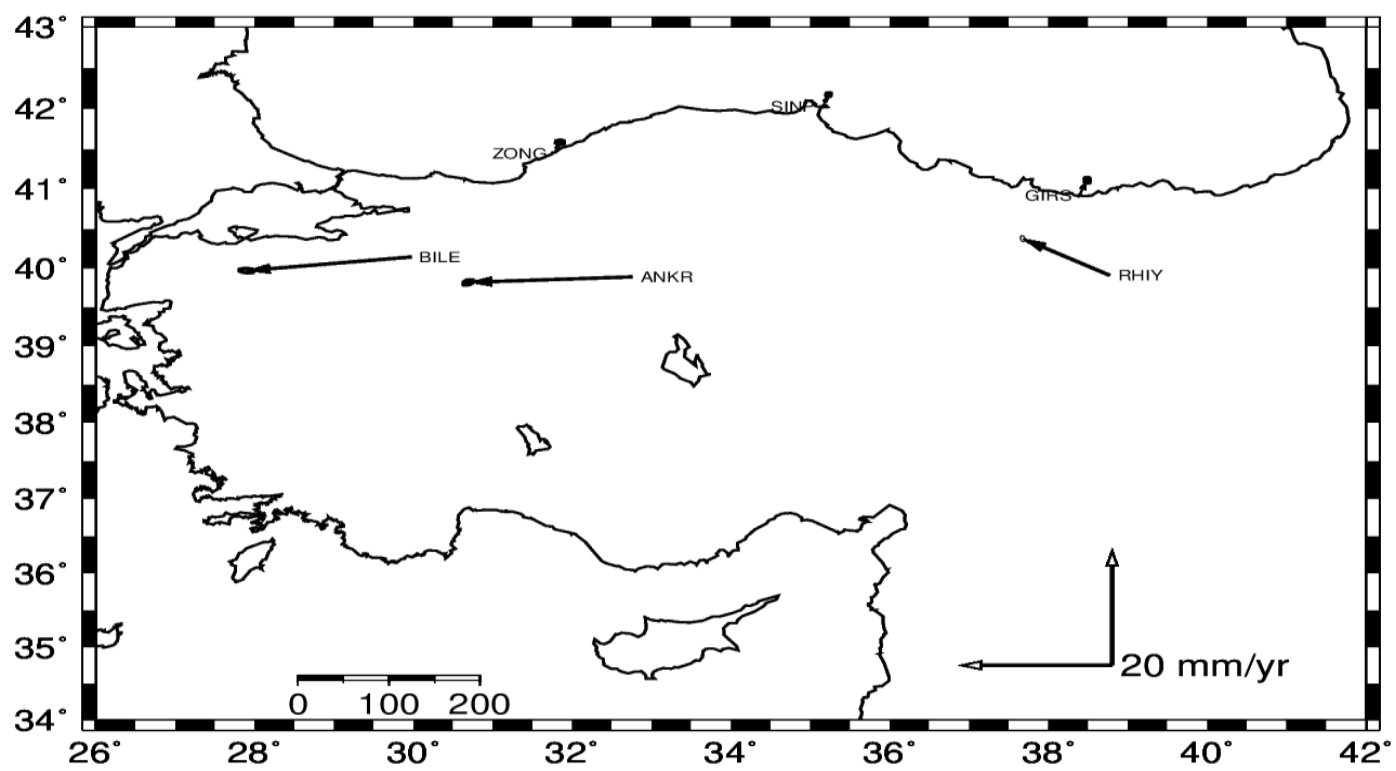

Şekil 2. Rölatif GNSS analizleri sonucu elde edilen nokta hızları haritası

Tablo 2. HNK analizlerinden elde edilen ORID sabit nokta hizları (mm/y1) ve standart sapmaları

\begin{tabular}{cccc}
\hline İstasyon & Kuzey $\pm \boldsymbol{\sigma}(\mathbf{m m})$ & Doğu $\pm \boldsymbol{\sigma}(\mathbf{m m})$ & Yukarı $\pm \boldsymbol{\sigma}(\mathbf{m m})$ \\
\hline RHIY & $6.05 \pm 0.76$ & $-11.46 \pm 1.21$ & $-0.36 \pm 3.28$ \\
GIRS & $2.42 \pm 0.82$ & $0.91 \pm 0.84$ & $-1.34 \pm 3.76$ \\
SINP & $1.98 \pm 0.81$ & $0.73 \pm 0.76$ & $-2.31 \pm 2.94$ \\
ANKR & $-0.74 \pm 0.74$ & $-21.01 \pm 1.01$ & $-3.83 \pm 4.12$ \\
ZONG & $1.98 \pm 0.82$ & $0.73 \pm 0.91$ & $-2.31 \pm 3.98$ \\
BILE & $-2.09 \pm 0.83$ & $-21.56 \pm 0.93$ & $-0.32 \pm 4.11$ \\
\hline
\end{tabular}

Tablo 1 ve 2'de verilen hız değerleri arasındaki farklar Kuzey, Doğu ve Yukarı bileşenler için elde edilmiş ve tek anlamlı ifade edilmek üzere 3B konum hatası da hesaplanarak Tablo 3'de sunulmuştur.

Tablo 3. Rölatif ve HNK yöntemlerinden elde edilen hızlara ait farklar ve 3B ifadesi (mm/yıl)

\begin{tabular}{ccccc}
\hline İstasyon & Kuzey & Doğu & Yukarı & 3B Konum \\
\hline RHIY & 0.24 & 0.14 & -0.73 & 0.78 \\
GIRS & 0.13 & 0.10 & -0.61 & 0.63 \\
SINP & -0.02 & 0.04 & -0.05 & 0.07 \\
ANKR & -0.20 & -0.34 & 0.66 & 0.77 \\
ZONG & -0.13 & -0.03 & -2.38 & 2.38 \\
BILE & -0.26 & 0.11 & -0.4 & 0.49 \\
\hline
\end{tabular}




\section{Tartışma ve Sonuç}

HNK ve rölatif GNSS analizlerinden elde edilen ve Tablo 1 ve 2'de sunulan hiz kestirim değerlerine ait standart sapmalar incelendiğinde, HNK yönteminden elde edilen standart sapma değerlerinin 0.5 ile $1.5 \mathrm{~mm}$ seviyelerinde daha yüksek olduğu görülmektedir. Tablo 3'de söz konusu iki yöntemden elde edilen hiz kestirim farklarının ise Kuzey, Doğu ve Yukarı bileşenler için 0-2.4 $\mathrm{mm} / \mathrm{y} 1 \mathrm{l}$ seviyeleriyle sinırlı kaldığ 1 görülmektedir. Tablo 3'te bulunan 3B konum hatası incelendiğinde tüm istasyonlar için hız kestirim farklılıklarının 0.1-2.4 mm seviyeleri aralığında olduğu görülmüştür.

Her iki yöntemden elde edilen hassasiyet ve koordinat değerleri arasındaki farklılaşmanın iki temel sebebi olduğu düşünülmektedir. Bunlardan ilki, rölatif GNSS yöntemiyle konum belirlemede, alıcı saati hatası ve başlangıç tamsayı belirsizliği tamamen elemine edilebilirken, HNK yönteminde alıcı saati hatası kestirilmekte, başlangıç tamsayı belirsizliği ise yakınsama suretiyle elde edilmektedir. Diğeri ise, rölatif GNSS analizleriyle istasyonlar arasındaki baz uzunluğu kestirilmekte, HNK yönteminde ise doğrudan uydu-alıc1 arasındaki mesafe bilgisi ile koordinatlar elde edilmektedir. Bu nedenle, çok düşük seviyelerde (birkaç $\mathrm{mm}$ ) de olsa bu farklılık doğal karşılanmıştır.

$\mathrm{Bu}$ çalışmada, son yıllarda oldukça popüler bir nokta konum belirleme yöntemi olan HNK yönteminin kabuk deformasyonu belirleme çalışmalarında kullanılabilirliği, rölatif GNSS analizi yöntemiyle karşılaştırılarak değerlendirilmiştir. Hiz kestirim değerleri ve standart sapmalar arasindaki farklilıklar incelendiğinde, sabit ya da hareketli noktalar için elde edilen değerlerin birkaç $\mathrm{mm}$ sınırlarını geçmediği ve yöntemin bilimsel yerkabuğu deformasyonu belirleme çalışmalarında kullanılabileceği ortaya çıkmaktadır. Diğer taraftan, Tablo 3 ile verilen farklar, kabuk deformasyonu belirleme çalışmalarında sıklıkla başvurulan gerinim analizleri için de farklılık oluşturmayacak kadar küçüktür. Ayrıca HNK yönteminin, ölçü planı ve ăg geometrisindeki değişikliklerden etkilenmemesi, datum dönüşümü için referans istasyona ihtiyaç duymaması, hızlı ve kolay analiz edilebilmesi gibi birçok avantaj göz önünde bulundurulduğunda, kabuk deformasyonu belirleme çalışmalarında, rölatif GNSS analiz yöntemi yerine tercih edilmesi oldukça makul görülmektedir. Ancak, bu çalışmada 24 saatlik gözlemler eşliğinde $\mathrm{mm}$ seviyelerinde farklılık elde edildiği ve gözlem süresinin kısaldığ 1 durumlarda HNK yönteminin performansının düşebileceği unutulmamalıdır.

\section{Kaynaklar}

Amiri-Simkooei, A.R., Alaei-Tabatabaei, S.M., Zangeneh-Nejad, F. and Voosoghi, B., 2017. Stability Analysis of Deformation-Monitoring Network Points Using Simultaneous Observation Adjustment of Two Epochs. Journal of Surveying Engineering, 143(1), 04016020 .

Aydin, C., Uygur, S.Ö., Cetin, S., Özdemir, A. ve Dogan, U., 2019. Ability of GPS PPP in 2D Deformation Analysis With Respect to GPS Network Solution. Survey Review, 51(366), 199-212.

Baarda, W., 1968. A testing Procedure for Use in Geodetic Networks. Publication on Geodesy, New Series, 2.

Bahadur, B. and Nohutcu, M., 2018. PPPH: a MATLAB-Based Software for Multi-GNSS precise Point Positioning Analysis. GPS solutions, 22(4), 113.

Herring, T.A., King, R.W. ve McClusky, S.C., 2010. Introduction to GAMIT/GLOBK. Massachusetts Institute of Technology, Cambridge, Massachusetts.

Nistor, S. ve Buda, A.S., 2015. Ambiguity Resolution in Precise Point Positioning Technique: A Case Study. Journal of Applied Engineering Sciences, $5(1), 53-60$.

Rajner, M. ve Liwosz, T., 2011. Studies of Crustal Deformation due to Hydrological Loading on GPS Height Estimates. Geodesy and Cartography.

Tétreault, P., Kouba, J., Héroux, P. ve Legree, P., 2005. CSRS-PPP: An Internet Service for GPS User Access to the Canadian Spatial Reference Frame. Geomatica, 59(1), 17-28.

Ustun, A., Tusat, E. ve Yalvac, S., 2010. Preliminary Results of Land Subsidence Monitoring Project in Konya Closed Basin between 2006-2009 by Means of GNSS Observations. Natural Hazards and Earth System Sciences, 10(6), 1151.

Yalvaç, S., 2019. Hassas Nokta Konumlama Yönteminin Doğruluğunun Mikro-Jeodezik Bir Ağda İncelenmesi. Gümüşhane Üniversitesi Fen Bilimleri Enstitüsü Dergisi, 9(3), 575-581.

Yalvac, S., 2020a. Validating InSAR-SBAS Results by Means of Different GNSS Analysis Techniques in Medium-and High-Grade Deformation Areas. 
Environmental Monitoring and Assessment, 192(2), 120.

Yalvaç, S., 2020b. Determining the Effects of the 2020 Elazığ-Sivrice/Turkey (Mw 6.7) Earthquake from the Surrounding CORS-TR GNSS Stations. Turkish Journal of Geosciences, 1(1), 15-20.

Yiğit, C.Ö., Kızılarslan, M. ve Çalışkan, E., 2016a. GPS-PPP ve GPS/GLONASS-PPP Yöntemlerinin Konum Belirleme Performanslarının Ölçü Süresine Bağlı Olarak Değerlendirilmesi. Harita Teknolojileri Elektronik Dergisi, 8(1), 22-39.
Yigit, C. O., Coskun, M. Z., Yavasoglu, H., Arslan, A., ve Kalkan, Y., 2016b. The Potential of GPS Precise Point Positioning Method for Point Displacement Monitoring: A case study. Measurement, 91, 398-404.

Zhou, F., Dong, D., Li, W., Jiang, X., Wickert, J. ve Schuh, H., 2018. GAMP: An Open-Source Software of Multi-GNSS Precise Point Positioning Using Undifferenced and Uncombined Observations. GPS Solutions, 22(2), 33 . 